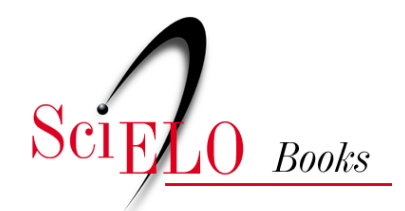

\title{
Capítulo VI - Os saberes tradicionais e locais e as indicações Geográficas o caso das plantas medicinais do Brasil
}

\author{
Lucia Regina Rangel de Moraes Valente Fernandes \\ Sandra Aparecida Padilha Magalhães Fraga \\ Vanise Baptista da Costa
}

\section{SciELO Books / SciELO Livros / SciELO Libros}

FERNANDES, L.R.M.V., FRAGA, S.A.P.M., and COSTA, V.B. Os saberes tradicionais e locais e as indicações Geográficas: o caso das plantas medicinais do Brasil. In: SANTOS, M.G., and QUINTERO, M., comps. Saberes tradicionais e locais: reflexões etnobiológicas [online]. Rio de Janeiro: EDUERJ, 2018, pp. 126-147. ISBN: 978-85-7511-485-8. https://doi.org/10.7476/9788575114858.0008.

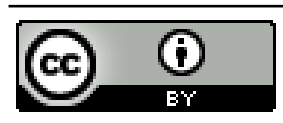

All the contents of this work, except where otherwise noted, is licensed under a Creative Commons Attribution 4.0 International license.

Todo o conteúdo deste trabalho, exceto quando houver ressalva, é publicado sob a licença Creative Commons Atribição 4.0.

Todo el contenido de esta obra, excepto donde se indique lo contrario, está bajo licencia de la licencia Creative Commons Reconocimento 4.0 . 


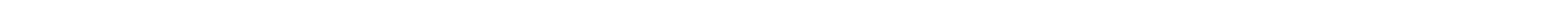




\title{
CAPÍTULO VI \\ Os saberes tradicionais e locais e as indicaçôes geográficas: o caso das plantas medicinais do Brasil
}

\author{
Lucia Regina Rangel de Moraes Valente Fernandes \\ Sandra Aparecida Padilha Magalhầes Fraga \\ Vanise Baptista da Costa
}

\section{Apresentaçăo}

No Brasil, o conhecimento tradicional sobre plantas medicinais ${ }^{1}$ tem origem na herança gerada por diversas etnias (indígena, negra e europeia) e gradativamente vem contribuindo para o estabelecimento da medicina tradicional brasileira - MTB. Esta construção cultural aliada a uma megabiodiversidade possibilita ao país ser um celeiro de conhecimentos sobre o uso sustentável e a conservação das espécies vegetais.

Esse conhecimento utilizado por diversas etnias indígenas e populações tradicionais está sendo alvo de estudos científicos que vêm apontando os efeitos benéficos do uso terapêutico de diversas espécies de plantas, além de gerar grande interesse das indústrias nacionais e, principalmente, das internacionais.

Por esta razão, nas últimas décadas, países detentores da biodiversidade, como o Brasil, sofrem intensamente com a apropriação dos seus recursos naturais e saberes locais e tradicionais. Verifica-se que as populações indígenas e comunidades tradicionais não vêm recebendo qualquer tipo de benefício pelos que fazem uso destes recursos para obter ganhos econômicos com produtos comerciais (MMA, 2013). Observa-se que ain-

1 De acordo com a RDC n. 14, publicada em 05 de abril de 2010, da Agência Nacional de Vigilância Sanitária (ANVISA), planta medicinal é "espécie vegetal, cultivada ou não, utilizada com propósitos terapêuticos". 
da são insuficientes os mecanismos legais de proteção ao uso e conservação da biodiversidade brasileira.

Outro aspecto importante a considerar é a criação de unidades de conservação (UC) em terras antes habitadas por várias gerações de grupos locais ou tradicionais, muitas vezes impactando na perda dos seus territórios, da sua identidade cultural e ameaçando a sua subsistência, bem como a transmissão dos seus saberes para as próximas gerações.

No Brasil, um marco importante aconteceu em 1988 com a promulgação da Constituição Federal (CF), na qual foram reconhecidos os direitos inerentes às populações indígenas e aos descendentes de escravos, os quilombolas. Não obstante abrindo um precedente de reconhecimento das populações tradicionais do país.

No contexto internacional, um grande marco ocorreu em 1992 na Conferência das Nações Unidas sobre o Meio Ambiente e o Desenvolvimento (ECO-92), realizada no Rio de Janeiro, com a assinatura da Convenção da Diversidade Biológica (CDB). Nela, foram previstas normas e princípios para reger o uso e a proteção da diversidade biológica em cada país signatário, tornando-se o principal instrumento jurídico para a proteção da biodiversidade no contexto internacional. Além disso, enfatiza a proteção aos conhecimentos associados à biodiversidade, visando garantir aos seus detentores a repartição justa e equitativa dos benefícios oriundos da utilização desses conhecimentos (MMA, 2013).

A Convenção foi assinada por 175 países durante a ECO-92 e mais tarde ratificada por 168 países, incluindo o Brasil, por meio do Decreto n. ${ }^{\circ}$ 2.519 de 16 de março de 1998.

Em nosso país, a matéria foi regulada pela Medida Provisória n. ${ }^{\circ}$ 2.18616 de 23 de agosto de 2001, gerando um Marco Regulatório sobre o acesso à amostra de patrimônio genético nativo e acesso ao conhecimento tradicional associado. A Medida Provisória também estabeleceu o Conselho de Gestão do Patrimônio Genético - CGen, como a autoridade nacional com função normativa e deliberativa sobre as autorizações de acesso e remessa.

Em 2006, o governo federal estabeleceu diretrizes para atuar na área de plantas medicinais e fitoterápicos, aprovando a Política Nacional de Práticas Integrativas e Complementares (PNPIC, 2006) no Sistema Único de Saúde (SUS) e a Política Nacional de Plantas Medicinais e Fitoterápicos (PNPMF, 2006). Estas iniciativas governamentais visaram ao desenvolvimento de ações para assegurar o acesso seguro e o uso racional de plantas 
medicinais e fitoterápicos em nosso país, ao desenvolvimento de tecnologias e inovações, ao fortalecimento das cadeias e dos arranjos produtivos, ao uso sustentável da biodiversidade brasileira e ao desenvolvimento do Complexo Produtivo da Saúde (Decreto n. ${ }^{\circ}$ 5.813, de 22 de junho de 2006).

Apesar dos avanços, a implementação destas políticas ainda requer um longo caminho pela frente, e, para tal fim, foi desenvolvido o Programa Nacional de Plantas Medicinais e Fitoterápicos (PNPMF), objetivando colocar em prática as diretrizes priorizadas na Política Nacional de Plantas Medicinais e Fitoterápicos (PNPMF).

Paralelamente, como instituição que desempenha papel essencial na interface dos sistemas de Ciência e Tecnologia e Saúde, a Fundação Oswaldo Cruz (Fiocruz) vem participando da gestão da Política e do Programa Nacional de Plantas Medicinais e Fitoterápicos, em cooperação com a Secretaria de Ciência, Tecnologia e Insumos Estratégicos do Ministério da Saúde, contribuindo para a exploração sustentável da biodiversidade, por meio de ações implementadas por vários ministérios, em parceria com instituições da sociedade civil, estados e municípios (Relatório Fiocruz, 2012). Todavia, neste trabalho de pesquisa, enfocaremos o papel estratégico da Fiocruz na implementação da décima segunda diretriz da PNPMF (s. p.), que estabelece a necessidade de "fortalecer e aperfeiçoar os mecanismos governamentais de proteção da propriedade intelectual na área de plantas medicinais e fitoterápicos”, desde o uso caseiro e comunitário ao desenvolvimento da pesquisa científica e fabricação de medicamentos industrializados.

No Brasil, no âmbito da propriedade intelectual, a Lei n. ${ }^{\circ} 9.279$ de 14 de maio de 1996, Lei da Propriedade Industrial (LPI), prevê a figura jurídica da Indicação Geográfica (IG), instrumento que apresenta potencial para proteger os aspectos como a qualidade de produtos gerados em determinadas regiões, incluindo o saber fazer tradicional, a forma de produção, a qualidade do clima e do solo. Portanto, apresenta um diferencial importante sobre os demais produtos pelo valor agregado, seja pelas condições do meio ambiente, seja pela reputação da produção.

Nessa perspectiva, observa-se que, no contexto brasileiro, a forma de plantio e de manejo das espécies vegetais comumente desenvolvidas pelas populações locais ou tradicionais aliadas às condições ambientais influenciam diretamente nas características do princípio ativo das plantas. 
Por essa razão, é sugerida a possibilidade de utilizar a figura jurídica da Indicação Geográfica (IG) como ferramenta coletiva de valorização de território e proteção de comunidades locais, tendo como fator estratégico a promoção da forma tradicional e local de desenvolvimento da produção, valorização dos produtos, preservação da biodiversidade e do conhecimento, e possibilita, assim, a sustentabilidade social e econômica dos produtores locais.

\title{
A Indicaçăo Geográfica
}

A propriedade intelectual no mundo obteve extraordinária importância a partir de meados do final do século XX, principalmente com a criação da Organização Mundial da Propriedade Intelectual (OMPI), em 1967, com o surgimento da Organização Mundial do Comércio (OMC), em 1995, em substituição ao Acordo Geral de Tarifas e Comércio (GATT), e pela celebração de Acordos Internacionais de grande relevância. Abrangem os direitos vinculados à capacidade criativa humana e as criações intelectuais, além de serem imprescindíveis ao crescimento econômico das nações.

A Convenção da Organização Mundial da Propriedade Intelectual (OMPI, 1967, artigo 2. ${ }^{\circ}$ ) define a Propriedade Intelectual como:

\begin{abstract}
A soma dos direitos relativos às obras literárias, artísticas e científicas, às interpretações dos artistas intérpretes e às execuções dos artistas executantes, aos fonogramas e às emissões de radiodifusão, às invenções em todos os domínios da atividade humana, às descobertas científicas, aos desenhos e modelos industriais, às marcas industriais, comerciais e de serviço, bem como às firmas comerciais e denominações comerciais, à proteção contra a concorrência desleal e todos os outros direitos inerentes à atividade intelectual nos domínios industrial, científico, literário e artístico.
\end{abstract}

No Brasil, a Constituição Federal de 1988 (Brasil, 1988) inovou ao assegurar garantia constitucional aos direitos de propriedade intelectual e vinculá-los à categoria de direitos fundamentais, como prevê o artigo 5. ${ }^{\circ}$ e incisos XXVII e XXIX: 
Artigo 5.: Todos são iguais perante a lei, sem distinção de qualquer natureza, garantindo-se aos brasileiros e aos estrangeiros residentes no País a inviolabilidade do direito à vida, à liberdade, à igualdade, à segurança e à propriedade, nos termos seguintes: Inciso XXVII - Aos autores pertence o direito exclusivo de utilização, publicação ou reprodução de suas obras, transmissível aos herdeiros pelo tempo que a lei deixar.

Inciso XXIX - A lei assegurará aos autores de inventos industriais privilégio temporário para sua utilização, bem como proteção às criações industriais, à propriedade das marcas, aos nomes de empresas e outros signos distintivos, tendo em vista o interesse social e o desenvolvimento tecnológico e econômico do país.

A propriedade intelectual no Brasil é regida pela seguinte legislação: Lei n. ${ }^{\circ}$ 9.279/1996 - Lei da Propriedade Industrial (LPI); Lei n. ${ }^{\circ}$ 9.610/1998 - Lei de Direitos do Autor; Lei n. ${ }^{\circ}$ 9.456/1997 - Lei da Proteção de Cultivares; e Lei n. ${ }^{\circ}$ 9.609/1998 - Lei da Proteção da Propriedade Intelectual de Programas de Computador (Lei de Software).

Destaca-se a Propriedade Industrial como um ramo da Propriedade Intelectual, que trata das criações intelectuais voltadas para as atividades da indústria, comércio e prestação de serviços, e engloba a proteção das invenções (patente de invenção e modelo de utilidade), desenhos industriais, marcas, indicações geográficas, além da repressão da concorrência desleal.

No âmbito nacional, o Sistema de Propriedade Industrial é constituído pela Lei da Propriedade Industrial, pela Convenção da União de Paris (CUP) e por alguns Tratados Internacionais - Acordo sobre os Aspectos dos Direitos de Propriedade Intelectual Relacionados ao Comércio (TRIPS), Tratado de Cooperação em Matéria de Patentes (PCT) -, assim como pelos Atos Normativos e Resoluções do Instituto da Propriedade Industrial (INPI).

O INPI é o órgão responsável pela aplicação da legislação referente à Propriedade Industrial e tem como principal função: analisar e julgar os pedidos de patentes de invenção, modelos de utilidade, desenhos industriais, marcas, aprovar e averbar os contratos de transferência a de tecnologia e pelo reconhecimento das Indicações Geográficas.

A Indicação Geográfica (IG) é considerada um ativo intangível no âmbito da propriedade industrial e se constitui como uma ferramenta coleti- 
va de proteção e valorização de produtos tradicionais associados a determinados territórios. Não obstante visa promover e garantir a qualidade de produtos de origem geográfica de renome comprovado, ressaltando o saber fazer tradicional, a forma de produção e costumes, além de fatores ambientais como a qualidade do clima e do solo etc.

Observa-se que os produtos desenvolvidos nas regiões protegidas por Indicações Geográficas (IG) potencialmente adquirem um diferencial importante sobre os demais pelo valor que agregam, seja pela reputação da produção, seja pelas condições do meio ambiente.

Historicamente, algumas regiões no mundo e os seus produtos especiais, foram desenvolvendo grande prestígio e conquistaram aumento de preços. Em compensação, acabou gerando falsificações e má utilização dos nomes das regiões. A partir deste cenário, a necessidade de garantir e proteger a qualidade e a origem dos produtos gerou legislações e acordos comerciais entre os países, com vistas à proteção contra a concorrência desleal e as falsas indicações de procedência.

Datada de 1883, a Convenção da União de Paris (CUP) foi o marco inicial da Propriedade Industrial e foi considerada um dos mais importantes diplomas internacionais sobre a matéria, estabelecendo padrões mínimos de proteção que foram adotados pelos países signatários. Foi o primeiro acordo internacional de proteção às Indicações de Procedência. O Brasil sempre esteve ligado à discussão sobre Propriedade Intelectual em nível internacional, sendo um dos onze países a assinar a CUP. A Convenção já sofreu algumas revisões desde a sua assinatura.

Em 1891, o Acordo de Madrid reprime as falsas indicações de procedência e o uso de expressões que levassem o consumidor ao erro, estabelecendo no seu artigo $1 .^{\circ}$ :

Todo produto que trouxer indicação falsa de sua procedência, na qual direta ou indiretamente se mencionar como país ou lugar de origem um dos países contratantes ou algum lugar em qualquer deles situado, será apreendido no ato da importação em cada um dos referidos países.

No entanto, como os mecanismos de proteção às Indicações Geográficas previstos nos acordos anteriores ainda não se mostraram suficientes, em 1958, foi assinado o Acordo de Lisboa voltado especificamente para a 
proteção das denominações de origem, contudo sem a adesão do Brasil. O acordo previu que uma vez registrada a denominação de origem, esta também deveria ser reconhecida pelos países signatários do acordo. Foi o primeiro acordo propondo um registro internacional, e, justamente por este caráter restritivo, obteve pouca adesão. Na verdade, o acordo interessava basicamente aos países da Europa pelo grande número de registros de IGs.

Em 1994, surge o Acordo sobre os Aspectos dos Direitos de Propriedade Intelectual Relacionados ao Comércio (TRIPS). Este tratado fez parte do Acordo que constituiu a Organização Mundial do Comércio (OMC), que estabeleceu padrões mínimos de proteção da Propriedade Intelectual no mundo, além de relacionar questões de propriedade industrial ao comércio. No que concerne às Indicações Geográficas estabeleceu o seguinte:

\begin{abstract}
Para os fins deste Acordo, entende-se indicações geográficas indicações que identifiquem um produto como originário do território de um Membro, ou região ou localidade deste território, quando determinada qualidade, reputação ou outra característica do produto seja essencialmente atribuída à sua origem geográfica (TRIPS, 1994, artigo 22, parágrafo $1 .^{\circ}$ ).
\end{abstract}

O Brasil foi um dos primeiros a assinar esse acordo que foi implementado no país por meio da Lei 9.279/1996, a Lei de Propriedade Industrial (LPI), que regula as Indicações Geográficas (IG). Contudo, a Instrução Normativa n. ${ }^{\circ} 25$ de 21 de agosto de 2013, do Instituto Nacional da Propriedade Industrial - INPI, estabelece as condições para o registro destes instrumentos.

A legislação nacional apresenta duas espécies de Indicações Geográficas, cada qual correspondendo a um instrumento jurídico específico, conforme rezam os artigos 176, 177 e 178, da Lei n. ${ }^{\circ}$ 9.279/1996:

Art. 176. Constitui indicação geográfica a indicação de procedência ou a denominação de origem.

Art. 177. Considera-se indicação de procedência o nome geográfico de país, cidade, região ou localidade de seu território, que se tenha tornado conhecido como centro de extração, produção ou fabri- 
cação de determinado produto ou de prestação de determinado serviço.

Art. 178. Considera-se denominação de origem o nome geográfico de país, cidade, região ou localidade de seu território, que designe produto ou serviço cujas qualidades ou características se devam exclusiva ou essencialmente ao meio geográfico, incluídos fatores naturais e humanos (Brasil, 1996).

Diferentemente de outros ativos intangíveis previstos na LPI, a Indicação Geográfica, quando concedida, vigora por tempo indeterminado e tem cunho declaratório. É inalienável, indivisível, não pode ser licenciada e deve estar vinculada a uma área geográfica.

\section{As Indicaçôes Geográficas no desenvolvimento econômico e social}

Consideradas sinais distintivos coletivos, as Indicações Geográficas estão vinculadas ao interesse social e ao desenvolvimento tecnológico e econômico, assim como todos os direitos de propriedade intelectual. Para Locatelli (2009), no contexto dos direitos relativos à propriedade intelectual, as Indicações Geográficas são capazes de fomentar a economia de um país pelo fato de diferenciar os produtos ou serviços pela sua origem.

As Indicações Geográficas são ferramentas coletivas de proteção e promoção de produtos com valor agregado advindos de suas heranças histórico-culturais. Este sistema de proteção intelectual possibilita que as regiões promovam seus produtos com direito reservado aos produtores da região de abrangência. Conforme Ascensão (2005), as Indicações Geográficas diferenciam-se de outros direitos industriais não por se referirem a um sujeito ou sujeitos determinados, mas a um conjunto de pessoas geograficamente delimitado.

O conceito de Indicação Geográfica vem sendo desenvolvido ao longo do tempo a partir da constatação de que alguns produtos de determinados lugares apresentavam qualidades especiais atribuídas à sua procedência, à sua origem geográfica. Os produtos apresentavam um diferencial a partir de características como o modo de fazer tradicional, o solo, o clima, tudo relacionado as regiões de origem. 
Segundo Tonietto (2003, pp. 126-7):

[...] as indicações geográficas possibilitam a valorização e a proteção de produtos cujas qualidades e características são fruto dos fatores naturais (aqueles sobre os quais o homem não pode ter influência direta: latitude, altitude; formação geológica, declividade, textura, estrutura e composição do solo; clima, chuvas, umidade do ar, temperaturas, insolação, ventos; flora natural, entre outros) e dos fatores humanos (sobre os quais o homem tem influência direta e que também são determinantes da qualidade e características dos produtos e que podem ser biológicos, agronômicos ou agroindustriais - exemplo no caso de vinho: porta-enxertos e variedades recomendadas, espaçamento, sistema de vinificação e envelhecimento, entre outros).

Outro aspecto importante característico do reconhecimento de uma IG é possibilitar aos produtores de uma região pouco desenvolvida competirem de forma quase igualitária com grandes empresas, tendo como grande diferencial o valor agregado ao seu produto pela forma natural e artesanal de produção ou características climáticas da região.

De acordo com Gonçalves (2008, p. 69):

[...] as indicações geográficas cumprem um papel essencial de diferenciação dos produtos no mercado. A indicação geográfica goza de estima junto ao público consumidor, permitindo identificar regiões e localidades que possuem produtos e serviços com características e qualidades diferenciadas. O consumo de produtos e serviços identificados como indicação geográfica reflete na economia, e no seu crescimento, da determinada região ou localidade reconhecida.

Kakuta (2006) afirma que as Indicações Geográficas são extremamente relevantes em regiões com baixo volume de produção, pois podem ajudar a manter e consagrar a forma tradicional de desenvolvimento da produção, além de ser uma ferramenta de preservação da biodiversidade, do conhecimento tradicional e dos recursos naturais da região. Nesse contexto, ainda podemos considerar as contribuições para a economia e 
o dinamismo das regiões, que proporcionam a valorização das propriedades rurais e estimulam o surgimento de novas empresas, aumentando as ofertas de empregos e serviços, como turismo e a gastronomia local, além de - e principalmente - diminuir o êxodo rural.

Conforme Gonçalves (2008, p. 69):

É inegável que a economia de um país não se sinta beneficiada se possuir produtos designados por indicações geográficas, visto que estas agregam valor ao produto. O interesse econômico do país corre em paralelo com o particular das empresas estabelecidas na localidade ou região.

O desenvolvimento tecnológico tem possibilitado a algumas regiões e produtores, em especial no agronegócio, disputarem mercados mais exigentes, agregando valor a seus produtos com o uso de certificações e indicando a qualidade de sua produção (Kakuta, 2006). As Indicações Geográficas representam um mecanismo que permite diferenciar os produtos de acordo com a região onde eles são produzidos, colocando selos, autorizados pelo Instituto Nacional da Propriedade Industrial - INPI.

De acordo com Santos (2002):

O que há num determinado lugar é a operação simultânea de várias técnicas, por exemplo, técnicas agrícolas, industriais, de transporte, comércio ou marketing, técnicas que são diferentes para um mesmo produto, segundo as respectivas formas de produção. Essas técnicas particulares, essas 'técnicas industriais', são manejadas por grupos sociais portadores de técnicas socioculturais diversas e se dão sobre um território que, ele próprio, em sua constituição material, é diverso, do ponto de vista técnico. São todas essas técnicas, incluindo as técnicas da vida, que nos dão a estrutura de um lugar.

O Brasil com seu vasto território, ecossistemas, diversidade cultural e conhecimentos tradicionais tem como fator estratégico e relevante ao desenvolvimento econômico e social do país a utilização da indicação Geográfica como proteção ao seu patrimônio nacional. Entendendo que 
desta forma será possível atribuir originalidade à produção brasileira, do saber fazer com produtos diferenciados, qualificados e certificados pela sua origem, estimulando a competitividade do mercado interno além de possibilitar a participação do país no mercado internacional (Tonietto, 2003).

Os pedidos de registro de indicação geográfica no Brasil são 92, até julho de 2014 considerando-se nacionais e estrangeiros, muito poucos, frente ao potencial do país, o que denota a necessidade do estabelecimento de políticas públicas de incentivo ao desenvolvimento deste bem imaterial, integrando governo, produtores e as instituições representativas dos setores produtivos. Além da difusão do conceito, é preciso formar competências nesta área do conhecimento e, mais do que nunca, identificar as regiões e produtos e serviços com potencial de proteção por meio deste ativo.

Atualmente foram concedidos 46 registros de Indicações Geográficas pelo INPI, sendo 38 nacionais (trinta Indicações de Procedência - IP e oito Denominações de Origem - DO) e oito estrangeiras (Denominações de Origem - DO).

As 38 Indicações Geográficas brasileiras concedidas vêm aumentando sua "visibilidade" no país, ampliando a atuação no mercado interno de produtos e serviços e, em determinados casos, melhorando a capacidade produtiva para atender mercados internacionais. Esse reconhecimento contribui para proteção de um patrimônio nacional e econômico, garantindo produtos de notoriedade, originalidade e de qualidade aos consumidores e estimulando o crescimento da economia regional.

O quadro 1 mostra as Indicações Geográficas concedidas pelo INPI em ordem cronológica de concessão. 


\section{Quadro 1. Indicaçôes Geográficas registradas no INPI em ordem cronológica}

\begin{tabular}{|c|c|c|c|c|}
\hline \multicolumn{5}{|c|}{ INDICAÇÕES GEOGRÁFICAS REGISTRADAS NO INPI } \\
\hline $\begin{array}{l}\text { Região dos Vinhos } \\
\text { Verdes (Portugal) }\end{array}$ & $\mathrm{DO}$ & PT & Vinhos & 1999 \\
\hline Cognac (França) & $\mathrm{DO}$ & FR & Destilado Vínico & 2000 \\
\hline Vale dos Vinhedos & IP & $\mathrm{BR} / \mathrm{RS}$ & Vinhos e espumantes & 2002 \\
\hline Franciacorta (Itália) & $\mathrm{DO}$ & IT & $\begin{array}{c}\text { Vinhos, espumantes e } \\
\text { bebidas alcoólicas }\end{array}$ & 2003 \\
\hline $\begin{array}{c}\text { Região do Cerrado } \\
\text { Mineiro }\end{array}$ & IP & $\mathrm{BR} / \mathrm{MG}$ & Café & 2005 \\
\hline $\begin{array}{c}\text { Pampa Gaúcho } \\
\text { da Campanha } \\
\text { Meridional }\end{array}$ & IP & $\mathrm{BR} / \mathrm{RS}$ & $\begin{array}{l}\text { Carne bovina e deri- } \\
\text { vados }\end{array}$ & 2006 \\
\hline Paraty & IP & $\mathrm{BR} / \mathrm{RJ}$ & $\begin{array}{l}\text { Aguardente tipo ca- } \\
\text { chaça e composta }\end{array}$ & 2007 \\
\hline $\begin{array}{l}\text { San Daniele } \\
\text { (Itália) }\end{array}$ & $\mathrm{DO}$ & IT & $\begin{array}{l}\text { Presunto defumado } \\
\text { cru }\end{array}$ & 2009 \\
\hline $\begin{array}{l}\text { Vale do Submédio } \\
\text { S. Francisco }\end{array}$ & IP & $\mathrm{BR} / \mathrm{BA} / \mathrm{PE}$ & $\begin{array}{l}\text { Uvas de mesa e man- } \\
\text { gas }\end{array}$ & 2009 \\
\hline Vale do Sinos & IP & $\mathrm{BR} / \mathrm{RS}$ & Couro acabado & 2009 \\
\hline $\begin{array}{l}\text { Litoral Norte } \\
\text { Gaúcho }\end{array}$ & $\mathrm{DO}$ & $\mathrm{BR} / \mathrm{RS}$ & Arroz & 2010 \\
\hline Pinto Bandeira & IP & $\mathrm{BR} / \mathrm{RS}$ & Vinhos e espumantes & 2010 \\
\hline $\begin{array}{l}\text { Serra da Manti- } \\
\text { queira de Minas } \\
\text { Gerais }\end{array}$ & IP & $\mathrm{BR} / \mathrm{MG}$ & Café & 2011 \\
\hline $\begin{array}{l}\text { Região do Jalapão } \\
\text { do Estado do TO }\end{array}$ & IP & $\mathrm{BR} / \mathrm{TO}$ & $\begin{array}{c}\text { Artesanato em capim } \\
\text { dourado }\end{array}$ & 2011 \\
\hline Goiabeiras & IP & $\mathrm{BR} / \mathrm{ES}$ & $\begin{array}{c}\text { Artesanato em pane- } \\
\text { las de barro }\end{array}$ & 2011 \\
\hline Costa Negra & $\mathrm{DO}$ & $\mathrm{BR} / \mathrm{CE}$ & Camarão & 2011 \\
\hline Pelotas & IP & $\mathrm{BR} / \mathrm{RS}$ & $\begin{array}{l}\text { Doces tradicionais e } \\
\text { confeitaria/frutas }\end{array}$ & 2011 \\
\hline
\end{tabular}




\begin{tabular}{|c|c|c|c|c|}
\hline Serro & IP & $\mathrm{BR} / \mathrm{MG}$ & $\begin{array}{l}\text { Queijo Minas artesa- } \\
\text { nal do Serro }\end{array}$ & 2011 \\
\hline $\begin{array}{c}\text { Vales da Uva } \\
\text { Goethe }\end{array}$ & IP & $\mathrm{BR} / \mathrm{SC}$ & Vinhos de uva Goethe & 2012 \\
\hline São João Del-Rei & IP & $\mathrm{BR} / \mathrm{MG}$ & $\begin{array}{c}\text { Peças artesanais em } \\
\text { Estanho }\end{array}$ & 2012 \\
\hline Canastra & IP & $\mathrm{BR} / \mathrm{MG}$ & Queijo canastra & 2012 \\
\hline Franca & IP & $\mathrm{BR} / \mathrm{SP}$ & Calçados & 2012 \\
\hline Porto (Portugal) & DO & PT & $\begin{array}{l}\text { Vinho generoso } \\
\text { (vinho licoroso) }\end{array}$ & 2012 \\
\hline Pedro II & IP & $\mathrm{BR} / \mathrm{PI}$ & $\begin{array}{l}\text { Opalas preciosas e } \\
\text { joias artesanais }\end{array}$ & 2012 \\
\hline $\begin{array}{l}\text { Região Pedra Cari- } \\
\text { jó Rio de Janeiro }\end{array}$ & DO & $\mathrm{BR} / \mathrm{RJ}$ & $\begin{array}{l}\text { Gnaisse fitado miloní- } \\
\text { tico branco }\end{array}$ & 2012 \\
\hline $\begin{array}{l}\text { Região Pedra Ma- } \\
\text { deira Rio de Janeiro }\end{array}$ & DO & $\mathrm{BR} / \mathrm{RJ}$ & $\begin{array}{l}\text { Gnaisse fitado } \\
\text { milonítico claro }\end{array}$ & 2012 \\
\hline $\begin{array}{l}\text { Região Pedra Cinza } \\
\text { Rio de Janeiro }\end{array}$ & DO & $\mathrm{BR} / \mathrm{RJ}$ & $\begin{array}{l}\text { Gnaisse fitado } \\
\text { milonítico cinza }\end{array}$ & 2012 \\
\hline $\begin{array}{l}\text { Cachoeiro de } \\
\text { Itapemirim }\end{array}$ & IP & $\mathrm{BR} / \mathrm{ES}$ & Mármore & 2012 \\
\hline Linhares & IP & $\mathrm{BR} / \mathrm{ES}$ & Cacau em amêndoas & 2012 \\
\hline $\begin{array}{l}\text { Manguezais de } \\
\text { Alagoas }\end{array}$ & DO & $\mathrm{BR} / \mathrm{AL}$ & Própolis vermelha & 2012 \\
\hline Napa Valley (EUA) & DO & US & Vinhos & 2012 \\
\hline Vale dos Vinhedos & DO & $\mathrm{BR} / \mathrm{RS}$ & $\begin{array}{c}\text { Vinhos tinto, branco e } \\
\text { espumante }\end{array}$ & 2012 \\
\hline $\begin{array}{c}\text { Norte Pioneiro do } \\
\text { Paraná }\end{array}$ & IP & $\mathrm{BR} / \mathrm{PR}$ & Café & 2012 \\
\hline Paraíba & IP & $\mathrm{BR} / \mathrm{PB}$ & $\begin{array}{l}\text { Têxteis de algodão } \\
\text { colorido }\end{array}$ & 2012 \\
\hline Região de Salinas & IP & $\mathrm{BR} / \mathrm{MG}$ & $\begin{array}{l}\text { Aguardente de cana } \\
\text { tipo cachaça }\end{array}$ & 2012 \\
\hline Divina Pastora & IP & $\mathrm{BR} / \mathrm{SE}$ & $\begin{array}{c}\text { Renda de agulha } \\
\text { em lacê }\end{array}$ & 2012 \\
\hline
\end{tabular}




\begin{tabular}{|c|c|c|c|c|}
\hline Porto Digital & IP & BR/PE & Serviços de TI & 2012 \\
\hline Altos Montes & IP & BR/RS & Vinhos e espumantes & 2012 \\
\hline $\begin{array}{c}\text { Champagne } \\
\text { (França) }\end{array}$ & DO & FR & Vinhos espumantes & 2012 \\
\hline Roquefort (França) & DO & FR & Queijo & 2013 \\
\hline São Tiago & IP & BR/MG & Biscoito & 2013 \\
\hline Alta Mogiana & IP & BR/SP & Café & 2013 \\
\hline Mossoró & IP & BR/RN & Melão & 2013 \\
\hline Cariri Paraibano & IP & BR/PB & Renda renascença & 2013 \\
\hline Monte Belo & IP & BR/RS & Vinhos e espumantes & 2013 \\
\hline $\begin{array}{c}\text { Região do Cerrado } \\
\text { Mineiro }\end{array}$ & DO & BR/MG & $\begin{array}{c}\text { Café verde em grão } \\
\text { grão ou moído }\end{array}$ & 2013 \\
\hline
\end{tabular}

Fonte: Instituto Nacional da Propriedade Industrial - INPI.

O registro de Indicação Geográfica (IG), no Brasil, principalmente no que se refere ao incentivo de práticas de uso de plantas medicinais e fitoterápicos, poderia gerar benefícios a toda a cadeia produtiva, além da saúde da população.

No contexto internacional, o panorama, no entanto, é outro. Tomando como exemplo a Europa, origem da proteção de IGs no mundo, como resultado de busca na Base DOOR da Comunidade Europeia, foram recuperadas, em julho de 2014, 1.232 IGs registradas, sendo 581 Denominações de Origem protegidas, 605 Indicações de Procedência Protegidas e 46 Especialidades Tradicionais Garantidas.

Na comunidade europeia, dezesseis regiões são protegidas por Indicações Geográficas que envolvem plantas, o que pode ser observado no quadro 2. Duas delas são da China e Índia. 


\section{Quadro 2. Indicaçồes Geográficas constantes na Base D00R da Comunida- de Europeia}

\begin{tabular}{|c|c|}
\hline \multicolumn{2}{|c|}{ INDICAÇÕES GEOGRÁFICAS - BASE DOOR DA COMUNIDADE EUROPEIA } \\
\hline PLANTAS/FLORES & ÁREA GEOGRÁFICA \\
\hline Óleo de Lavanda & Alpes - França \\
\hline Óleo de Bergamota & Calábria - Itália \\
\hline Camomila Bohemica & Bohemia - República Checa \\
\hline Camomila Hungria & $\begin{array}{l}\text { Szabolcs-Szatmár-Bereg, Borsod-Abaúj-Zemplén, } \\
\text { Heves, Jász-Nagykun-Szolnok, Hajdú-Bihar, Békés, } \\
\text { Csongrád, Bács-Kiskun e Peste - Hungria }\end{array}$ \\
\hline Chá de Darjeeling & Darjeeling - Índia \\
\hline Chá de Longjing & Xihu / Quiantang/Yuizhou - China \\
\hline $\begin{array}{l}\text { Zafferano di San Gimi- } \\
\text { niano }\end{array}$ & San Giminiano - Itália \\
\hline Zafferano L'Aquila & Áquila - Itália \\
\hline Alcaçuz e extrato Calábria & Calábria - Itália \\
\hline Açafrão de Dardena & Sardenha - Itália \\
\hline Azafrán de La Mancha & La Mancha - Espanha \\
\hline Azálea & Gante - Bélgica \\
\hline Cominho & República Checa \\
\hline Lúpulo & $\begin{array}{l}\text { Eriskirch, Friedrichshafen, Hagnau am Bodensee, } \\
\text { Immenstaad am Bodensee, Kressbronn am Bo- } \\
\text { densee, Langenargen, Markdorf, Meckenbeuren, } \\
\text { Neukirch, Oberteuringen e Tettnang, no distrito } \\
\text { do Lago de Constança (Bodenseekreis) - Alemanha }\end{array}$ \\
\hline Lúpulo 2 & $\begin{array}{l}\text { Hallertau abrange os Landkreisen Eichstätt, Frei- } \\
\text { sing, Kehlheim, Landshut, Nürnberger Land e } \\
\text { Pfaffenhofen. - Alemanha }\end{array}$ \\
\hline Lúpulo 3 & Žatecká chmelařská oblast - República Checa \\
\hline
\end{tabular}

Fonte: Base D00R da Comunidade Europeia. 
Não obstante, países emergentes como Índia e China vêm utilizando o ativo intangível das Indicações Geográficas como forma de valorizar e garantir a qualidade original de seus produtos tradicionais (Kakuta, 2006).

Nas últimas décadas, o governo brasileiro vem percebendo a relevância do papel das IGs e do seu potencial para o desenvolvimento econômico e social. Contudo, Santilli (2005) destaca que é fundamental a utilização de instrumentos alinhados a uma política de desenvolvimento territorial, social e humano, considerando a diversidade cultural do país. Segundo o autor:

[...] as Indicações Geográficas poderiam ser instrumentos úteis à diferenciação dos produtos gerados por povos tradicionais no mercado, agregando-lhes valor cultural e ambiental, oferecendo ao consumidor uma marca distintiva de sua tipicidade, beneficiando-se de nichos específicos de mercado (p. 201).

Pode ser, portanto, uma alternativa para a proteção dos direitos do conhecimento tradicional associado, assim como possibilitar aos produtores de regiões pouco desenvolvidas sustentabilidade, tendo como o grande diferencial o valor agregado ao seu produto, seja pelas condições do meio ambiente, seja pela reputação da produção, seja pelo diferencial de comércio justo. ${ }^{2}$

\section{Processo de Reconhecimento e Registro de Indicaçăo Geográfica}

- Organizar os produtores interessados no reconhecimento da Indicação Geográfica em uma instituição representativa;

- Realizar um levantamento histórico-cultural: identificar publicações em jornais, revistas, entrevistas, reportagens, livros e tra-

2 Comércio justo é uma "parceria comercial, baseada em diálogo, transparência e respeito, que busca maior equidade no comércio internacional. Ele contribui para o desenvolvimento sustentável, por meio de melhores condições de troca e garantia dos direitos para produtores e trabalhadores marginalizados". IFAT - International Federation of Alternative Trade. Disponível em: www.ifat.org. 
balhos científicos que comprovem que a região é conhecida pela produção de determinado produto ou serviço;

- Construir o Regulamento de Uso, constando as etapas do processo de produção, essencial para que o produto tenha garantia da origem e de rastreabilidade;

- Institucionalizar um Conselho Regulador que será responsável pela gestão, manutenção e preservação da Indicação Geográfica.

O pedido de registro de Indicação Geográfica deverá ser encaminhado ao Instituto Nacional da Propriedade Industrial - INPI por pessoa jurídica representativa dos produtores (natureza jurídica: associação, fundação ou cooperativa).

O Brasil, graças à sua natureza, congrega uma das maiores vegetações do planeta, aliada a uma sociodiversidade que detém um extraordinário conhecimento sobre a utilização de plantas para benefício da saúde. Por estas razões, tem potencial e vantagem competitiva para atender a um mercado promissor de plantas medicinais e fitoterápicos que cresce tanto no país quanto no resto do mundo.

Com base nesta biodiversidade e tradição no uso de plantas medicinais, tem capacidade para estabelecer um modelo de desenvolvimento próprio na área de saúde, promovendo as diversas práticas e formas de uso das plantas medicinais com segurança e eficácia, desde o uso caseiro e comunitário, ao desenvolvimento de pesquisas científicas e fabricação de medicamentos industrializados. Dessa forma, é um grande desafio melhorar o nosso sistema produtivo para atender a esse novo mercado, adotando práticas agrícolas adequadas no cultivo, no beneficiamento e na armazenagem da produção.

Muito embora as políticas públicas relacionadas ao uso de plantas medicinais tenham sido instituídas e congreguem avanços, como o Programa Nacional de Plantas Medicinais e Fitoterápicos (PNPMF), percebe-se que as regulamentações ambientais e sanitárias ainda não favorecem a participação do pequeno produtor urbano familiar nesse processo.

A prospecção de potencial de IG em determinadas regiões dá subsídios à fundamentação para uma possível defesa que venha a garantir a permanência de agricultores familiares e de sua sustentabilidade econômica e social. Para o estabelecimento de uma IG, a reputação da região 
terá que ser reconhecida pelo órgão competente em nível nacional, no caso o INPI, e, desta forma, deve-se comprovar que a região vem sendo habitada por gerações de agricultores.

Outro aspecto importante que deve ser considerado é a possibilidade da IG gerar mais segurança de sustentabilidade para os agricultores que dependem exclusivamente da agricultura para a subsistência, partindo da premissa que a IG possibilitará a abertura para novos mercados, além do impacto socioeconômico que poderá gerar como resultado o interesse por rotas turísticas.

Recomendamos, como fator estratégico, a utilização da proteção do ativo intangível pela origem geográfica (IG) como ferramenta coletiva de proteção e valorização do território, promoção da forma tradicional de desenvolvimento da produção, preservação da biodiversidade e do conhecimento tradicional, assim como possibilitar aos produtores da região sustentabilidade, tendo como o grande diferencial a reputação dos produtos reconhecida pelos consumidores.

Entende-se que o reconhecimento da Indicação Geográfica poderá:

- Garantir a preservação dos saberes coletivos, além de valorizar e estimular o desenvolvimento dos seus territórios;

- Garantir às populações tradicionais uma maior proteção contra a apropriação injusta de seus saberes;

- Promover a qualificação da cadeia produtiva com a introdução de normas básicas para os procedimentos e o desenvolvimento social das comunidades inseridas no entorno das áreas de cultivo.

É necessário que os estudos devem ser conduzidos especialmente no que concerne à busca de mais subsídios para a comprovação da reputação de regiões e que se iniciem processos de delimitação das áreas geográficas a serem protegidas por IG com o órgão pertinente, a julgar pelos obstáculos e os desafios para obtenção e manutenção da IG em função das restrições ambientais existentes nestas regiões.

Sugerimos a realização de estudos prospectivos das Indicações Geográficas de plantas medicinais protegidas nas diversas regiões da Europa. Dessa forma, será possível se apropriar de experiências de IGs reconhecidas e suas espécies - a Indicação de Procedência (IP) ou a Denominação de Origem (DO) -, assim como dos processos de instituição e manuten- 
ção para que a decisão seja tomada com subsídios reais nos casos de potenciais IGs no Brasil.

\section{Referências}

BRASIL. Constituição da República Federativa do Brasil. Brasília, 1988.

. "Decreto n. ${ }^{\circ} 1.355$, de 30 de dezembro de 1994". Acordo sobre aspectos dos direitos de propriedade intelectual relacionados ao comércio. Brasília, 1994.

. Presidência da República. "Lei n. ${ }^{\circ} 9.279$ de 14 de maio de 1996". Diário Oficial da União, Brasília, 1996.

. “Lei n. ${ }^{0}$ 9.456, de 25 de abril de 1997”. Institui a Lei de Proteção de Cultivares e dá outras providências. Brasília, 1997. Disponível em: http:// www.planalto.gov.br/ccivil_03/leis/L9456.htm. Acesso em: 14 jul. 2014.

. "Lei n. ${ }^{\circ}$ 9.609, de 19 de fevereiro de 1998”. Dispõe sobre a proteção da propriedade intelectual de programa de computador, sua comercialização no Pais, e dá outras providências. Brasília, 1998. Disponível em: http:// www.planalto.gov.br/ccivil_03/leis/19609.htm. Acesso em: 14 jul. 2014.

. "Lei n. 9 9.610, de 19 de fevereiro de 1998". Altera, atualiza e consolida a legislação sobre direitos autorais e dá outras providências. Brasília, 1998. Disponível em: http://www.planalto.gov.br/ccivil_03/leis/19610.htm. Acesso em: 14 jul. 2014.

. "Decreto n. ${ }^{\circ} 2.519$, de 16 de março de 1998”. Diário Oficial da República Federativa do Brasil, Brasília, 17 mar. 1998.

. Ministério da Saúde. "Decreto n. ${ }^{\circ}$ 5.813, de 22 de junho de 2006". Diário Oficial da União. Brasília, 2006. Disponível em: http://portal. saude.gov.br/portal/arquivos/pdf/portariafito.pdf. Acesso em: 14 jul. 2014.

. Ministério da Saúde. "Portaria n. 971, de 03 de maio de 2006". Aprova a Política Nacional de Práticas Integrativas e Complementares no 
SUS. Diário Oficial da União, Brasília, 2006c. Disponível em: http:// portal.saude.gov.br/portal/arquivos/pdf/portariafito.pdf. Acesso em: 14 jul. 2014.

. Ministério do Meio Ambiente. Disponível em: http://www.mma.gov. br/biodiversidade/biodiversidade-brasileira. Acesso em: 25 fev. 2013. Instituto Nacional da Propriedade Industrial - INPI. "Instrução Normativa n. ${ }^{\circ} 25$, de 25 de agosto de 2013”. Rio de Janeiro, 2013. Disponível em: http://www.inpi.gov.br/images/docs/instrucao_normativa_25_indicacoes_geograficas[2].pdf. Acesso em: 14 jul. 2014.

FUNDAÇÃO OSWALDO CRUZ. Relatório de Atividades da Fiocruz 20092011. Rio de Janeiro, 2012.

GONÇALVES, M. F. W. Propriedade Industrial e a proteção dos nomes geográficos: Indicações Geográficas, Indicações de Procedência e Denominações de Origem. Curitiba: Juruá, 2008.

KAKUTA, S. M. Indicações Geográficas: guia de resposta. Porto Alegre: SEBRAE/RS, 2006.

LISBOA. "Acordo de Lisboa, de 31 de outubro de 1958". Relativo à Proteção das denominações de origem e seu registro internacional. Organização mundial da propriedade intelectual, Genebra, 1997.

MADRID. "Acordo de Madrid, de 14 de abril de 1891". Relativo à repressão das indicações de procedência falsas ou enganosas nas mercadorias.

ORGANIZAÇÃO Mundial da Propriedade Intelectual. Denominações de origem e seu registro internacional. Genebra, 1997.

PARIS. Convenção da União de Paris - CUP. Disponível em: http://www. inpi.gov.br/images/stories/CUP.pdf. Acesso em: 14 jul. 2014.

SANTILLI, J. "As Indicações Geográficas e as Territorialidades Específicas das Populações Tradicionais, Povos Indígenas e Quilombolas". In LAGES, V. et al. (orgs.). Valorização de produtos com diferencial de qualidade e identidade: indicações geográficas e certificações para competitividade nos negócios. 1 ed. Brasília: Sebrae, 2005. 
SANTOS, A. S. R. Biodiversidade, bioprospecção, conhecimento tradicional e o futuro da vida. São Paulo, 2002. Disponível em: http://www.ccuec.unicamp.br/revista/infotec/artigos/silveira.html. Acesso em: 13 maio 2013.

TONIETTO, J. "O papel econômico e o atual tratamento jurídico das indicações geográficas". Anais do 23. Seminário Nacional da Propriedade Intelectual. São Paulo: Associação Brasileira da Propriedade Intelectual, 2003,pp. 126-9. 